\title{
Pressure-induced chlorine isotope fractionation among chlorine- bearing minerals
}

\author{
XI LIU $^{1}$, HAI-ZHEN WeI ${ }^{1}$ *, SHAO-YONG JiANG ${ }^{2}$, \\ ANTHONY E. WILLIAMS-JONES ${ }^{3}$, JiAN-JUN LU ${ }^{1}$ \\ ${ }^{1}$ Department of Earth Sciences and Engineering, Nanjing \\ University, Nanjing 210023, PR China \\ (haizhenwei@nju.edu.cn) \\ ${ }^{2}$ Faculty of Earth Resources, China University of Geosciences, \\ Wuhan 430074, PR China (shyjiang@cug.edu.cn) \\ ${ }^{3}$ Department of Earth and Planetary Sciences, McGill \\ University, 3450 University Street, Montreal, QC, Canada \\ H3A 0E8 (anthony.williams-jones@mcgill.ca)
}

Although it is believed that equilibrium fractionation of stable isotopes might not be significant at high temperature (Urey,1947) [1], the recent theoretical predictions indicate that pressure-induced shifts in typical stable isotope compositions cannot be ignored. In order to quantify the extent of chlorine isotope fractionation among chlorinebearing minerals and to evaluate the factors controlling chlorine isotope fractionation in terrestrial processes, the pressure effect of chlorine isotope fractionation for the major chlorine-bearing minerals (i.e., apatite-group minerals, muscovite, phlogopite, tremolite, marialite and metal halides) have been investigated by a density functional theory study.

At ambient P-T conditions, the reduced isotopic partition function ratio (i.e., $\beta$ factors) are strongly correlated with the metal-Cl bond length of the minerals, such that minerals in which chlorine is bonded to trivalent metals (e.g., $\mathrm{Al}^{3+}$ ) with shorter metal- $\mathrm{Cl}$ bonds have higher $\beta$-factor than minerals in which the chlorine is bonded to monovalent metals (e.g., $\mathrm{Na}^{+}$) with longer metal-Cl bonds. It is in an excellent agreement with the study by Schauble et al. (2003) [2]. As a result of a number of factors, including the adjacent atomic environment, the sites occupied by chlorine atoms in crystals, the Cl-metal coordination and the crystal density, the sensitivity of $10^{3} \ln \beta$ to pressure follows the sequence: halite $>$ fluorochlorapatite $>$ chlorapatite $>$ marialite $>$ hydroxylchlorapatite $>$ tremolite $>$ muscovite $>$ phlogopite.

The pressure-induced chlorine isotope fractionation should be well concerned, which may explain the relatively larger variations of chlorine isotopic composition in high P-T processes.

[1] Urey H.C. (1947). The thermodynamic properties of isotopic substances. J. Chem. Soc. (London), 562-581.

[2] Schauble E.A., Rossman G.R., Taylor H.P. (2003) Theoretical estimates of equilibrium chlorine-isotope fractionations. Geochim. Cosmochim. Acta 67, 3267-3281. 